\title{
Experience in the surgical management of 82 symptomatic herniated thoracic discs and review of the literature
}

Charles B. Stillerman, M.D., Thomas C. Chen, M.D., Ph.D., William T. Couldwell, M.D., Ph.D., Wei Zhang, M.D., Ph.D., and Martin H. Weiss, M.D.

University of North Dakota School of Medicine and Trinity Medical Center, Minot, North Dakota; and University of Southern California School of Medicine, Los Angeles, California

Object. The authors aimed to develop management strategies for the treatment of herniated thoracic discs and to define indications for selection of surgical approaches. Symptomatic thoracic discs requiring surgery are rare. Between 1971 and 1995,71 patients with 82 herniated thoracic discs were surgically treated by the authors. The treated group included 34 men and 37 women whose ages ranged from 19 to 75 years, with a mean age of 48 years. The most common sites of disc herniation requiring surgery were from T-8 to T-11. Evidence of antecedent trauma was present in $37 \%$ of the patients. Preoperative symptoms included pain (localized, axial, or radicular) in $54(76 \%)$ of the 71 patients, evidence of myelopathy that is, motor impairment in $43(61 \%)$, hyperreflexia and spasticity in 41 (58\%), sensory impairment $43(61 \%)$, and bladder dysfunction in $17(24 \%)$.

Methods. Radiological diagnosis for the patients in this series was accomplished by means of myelography, computerized tomography myelography, or magnetic resonance imaging. Classification of the disc location into two groups reveals that $94 \%$ were centrolateral and $6 \%$ were lateral. Evidence of calcification was present in $65 \%$ of patients, and in $7 \%$ intradural extension was noted at surgery. Ten patients (14\%) were found to have multiple herniations. Four surgical approaches were used for the removal of these 82 disc herniations: transthoracic in $49(60 \%)$, transfacet pedicle-sparing in $23(28 \%)$, lateral extracavitary in eight (10\%), and transpedicular in two (2\%). Postoperative evaluation revealed improvement or resolution of pain in $47(87 \%)$ of 54, hyperreflexia and spasticity in 39 $(95 \%)$ of 41 , sensory changes in $36(84 \%)$ of 43 , bowel/bladder dysfunction in 13 (76\%) of 17 , and motor impairment in 25 (58\%) of 43. Complications occurred in a total of $12(14.6 \%)$ of 82 discs treated surgically. Major complications were seen in three patients and included perioperative death from cardiopulmonary compromise, instability requiring further surgery, and an increase in the severity of a preoperative paraparesis.

Conclusions. Review of this series, with the attendant complications, together with evaluation of several contemporary thoracic disc series, has facilitated the authors' decision-making process when considering the comprehensive management of these patients, including the selection of a surgical approach.

\section{Key Words * thoracic spine * thoracic disc * disc herniation * discectomy * thoracic microdiscectomy}

Surgical treatment for herniated thoracic discs is rare and comprises between $0.15 \%$ and $4 \%$ of all disc

operations. $[1-5,8,10,15,23,26,28,31,39,50,56,57,64,66,68,70]$ Historically, treatment of this disorder has been problematic. In part this has been related to diagnostic delays resulting from both the infrequency of this disease and its lack of a characteristic presentation pattern. Moreover, the indications for surgery are not well established because the natural history of this disorder is not clearly defined. The presence of severe and/or progressive myelopathy is generally regarded as an absolute indication for surgery. The role of surgery as a means to control pain is controversial; it has been reported that radicular pain responds better to surgery than does nonradiating thoracic pain. $[36,48,67]$

Selection of the optimum surgical approach for disc removal is also controversial. In early series patients were treated with laminectomy, which resulted in suboptimal outcomes.[38,39,66,68,70] This presumably relates to the fact that the ventral force placed on the spinal cord by the herniated disc is inadequately reduced by removing only the lamina. $[39,40,68]$ When disc removal was performed via laminectomy, spinal cord manipulation was often not well tolerated.[5,12,17,38, 39,52,56,68,70] The limited space available for the spinal cord in this region and a comparatively tenuous blood supply are thought to increase the susceptibility of the spinal cord to injury during decompression. $[39,40,54,63,68,72]$ As a result of these early experiences, new approaches to the thoracic spine evolved that provided improved access to the ventral spinal canal and disc space.[14,16,21,24,25,31,34,38,39,42,48-50,52,53,68-70] However, despite facilitating ventral exposure of the disc, some of these procedures are associated with significant patient morbidity and are technically formidable to perform.[66,67]

The following report on our thoracic microdiscectomy series emphasizes presentation patterns, surgical treatment, and patient outcomes. Based on review of this experience and 13 other contemporary thoracic discectomy series, we have developed management 
schemes that consist of a comprehensive treatment algorithm and an attempt to define indications for selection of a surgical approach.

\section{CLINICAL MATERIAL AND METHODS}

\section{Patient Population}

Between 1971 and 1995, 71 patients underwent 82 thoracic microdiscectomies performed by the authors (60\% by M.H.W., $40 \%$ by C.B.S.). The patient population consisted of 34 men and 37 women whose ages ranged from 19 to 75 years, with a mean age of 48 years. There was a history of antecedent trauma in 26 patients $(37 \%)$.

Levels of herniation ranged from T-4 to L-1, and the most common sites of herniation were from T-8 to T-11 (54 discs, 66\%). The most common disc levels were T9-10 (21 discs, 26\%), T8-9 (19 discs, 23\%), and T10-11 (14 discs, 17\%). Seventy-five (91\%) of herniations were located between T-6 and T-11 (Fig.1). Ten (14\%) of the 71 patients presented with multiple disc herniations.

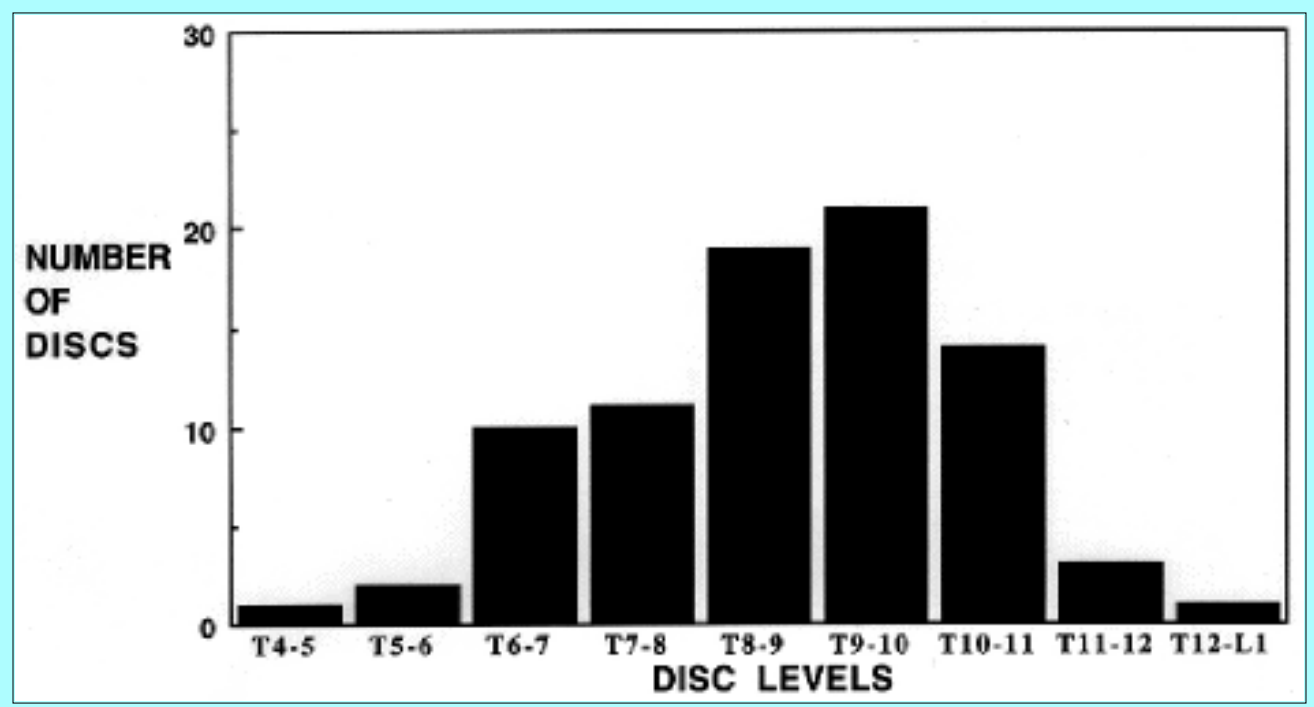

Fig. 1. Bar graph showing the surgically treated levels in this series of 82 thoracic disc herniations. Note that the majority of disc herniations were between T-8 and T-11 (66\%). The T6-11 levels were involved in more than $90 \%$ of the cases of herniation treated in this series. The most common levels of involvement were T9-10, T8-9, and T10-11, respectively. Relatively few herniations occurred at the thoracolumbar junction, T11-L1.

Discs were classified as centrolateral if the bulk of the herniation was medial to the lateral margin of the thecal sac and lateral if the majority of the disc was located lateral to the thecal sac. The majority of the 82 discs were centrolateral in location ( 77 discs, $94 \%)$.

Evidence of at least partial calcification on either plain x-ray films, computerized tomography (CT) scanning, magnetic resonance (MR) imaging, or during intraoperative inspection was present in $53(65 \%)$ of 82 discs; in six discs (7\%) we observed intradural extension at surgery. It should be noted that the majority of intradural penetrations occurred in densely calcified discs.

The patient's presenting signs and symptoms are listed in Fig. 2. The most common presenting symptom was pain, which occurred in $54(76 \%)$ of the 71 patients (Fig. 2 center). Of the patients with pain, three distinct presentation patterns existed. These included: 1) localized thoracic back pain in $22(41 \%) ; 2$ ) axial pain radiating down the thoracic spine into the lumbar and/or paralumbar spine or buttocks in $21(39 \%)$; and 3) radicular pain in $11(20 \%)$. The pain was generally characterized as moderate to severe in intensity. In patients with overlapping symptoms, the pain was classified according to the distribution in which it was most severe. However, it must be emphasized that not all symptomatic patients presented with a pain syndrome.

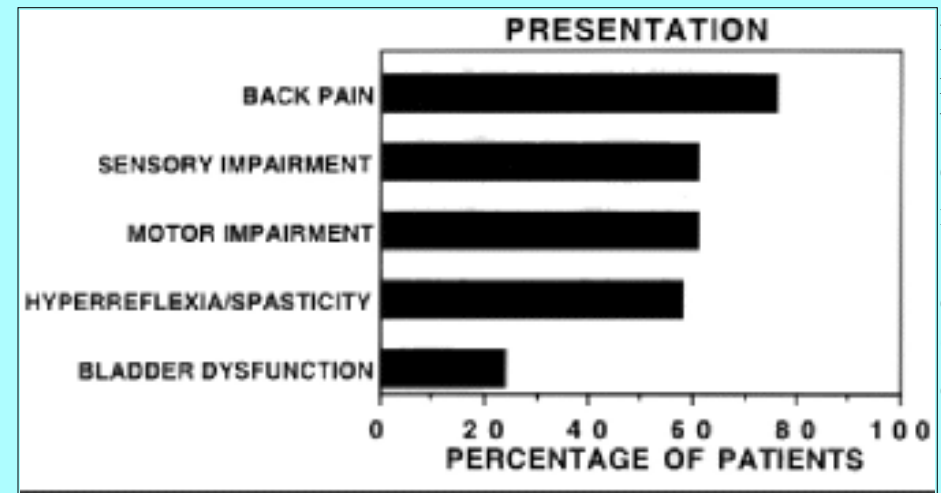

PATIENTS WITH PAIN AT PRESENTATION
Fig. 2. Presenting signs and symptoms. Upper: Histogram plots representing the percentage of patients in the present series with back pain and/or findings of myelopathy. Center and Lower: Pie charts. The most common complaint at presentation was that of pain in $76 \%$ of patients. Center: Three distinct pain distributions were seen. Patients with overlap between the different syndromes were classified based on the region of pain that was most severe. Lower: Of the $61 \%$ of patients found to have weakness, the majority demonstrated a spastic paraparesis. $\mathrm{TL}=$ thoracolumbar.

Sensory impairment, ranging from dysesthesias/paresthesias to complete sensory loss, was reported in $43(61 \%)$ of the patients. Bladder dysfunction was reported by 17 (24\%), with urgency being the most 


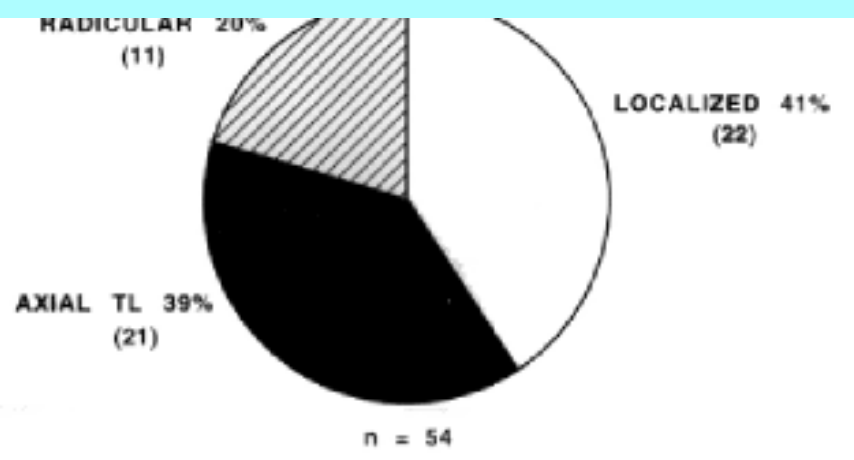

PATIENTS WITH MOTOR DEFICIT AT PRESENTATION

MONOPARESIS $28 \%$

(12)

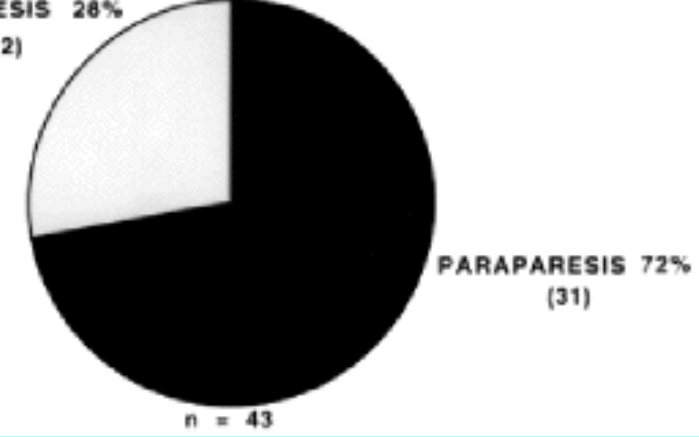

common complaint. Spasticity and hyperreflexia occurred in $41(58 \%)$ of patients, and a positive Babinski sign was seen in $39(55 \%)$. In our series, $17(24 \%)$ of 71 patients were free of pain and dysesthesias at presentation. However, 21 (30\%) of the patients had a normal neurological examination and underwent surgery for severe unrelenting pain (Fig. 2 upper).

Lower-extremity weakness was noted in $43(61 \%)$ of the patients. Paraparesis (31 patients, $72 \%$ ) was much more common than monoparesis (12 patients, $28 \%)$. Twenty-eight (39\%) of the 71 patients had no motor deficit (Fig. 2 lower).

\section{Neuroradiological Evaluation}

Prior to 1986 all patients underwent either myelography, CT scanning, or CT myelography. Radiological studies obtained in patients undergoing operation subsequent to 1986 included MR imaging for diagnosis and preoperative planning.

\section{Surgical Procedures}

The approaches used are shown in Fig. 3, which illustrates alternative surgical trajectories to the disc. The most common approach used in this series was the transthoracic. However, more recently the transfacet pedicle-sparing approach has been used with greater frequency,

comprising $23(70 \%)$ of 33 discs removed during the last 6 years. The lateral extracavitary approach was used for eight discectomies and the transpedicular approach for two. These surgeries have previously been well described.[16,34,39,50,52,53,66]

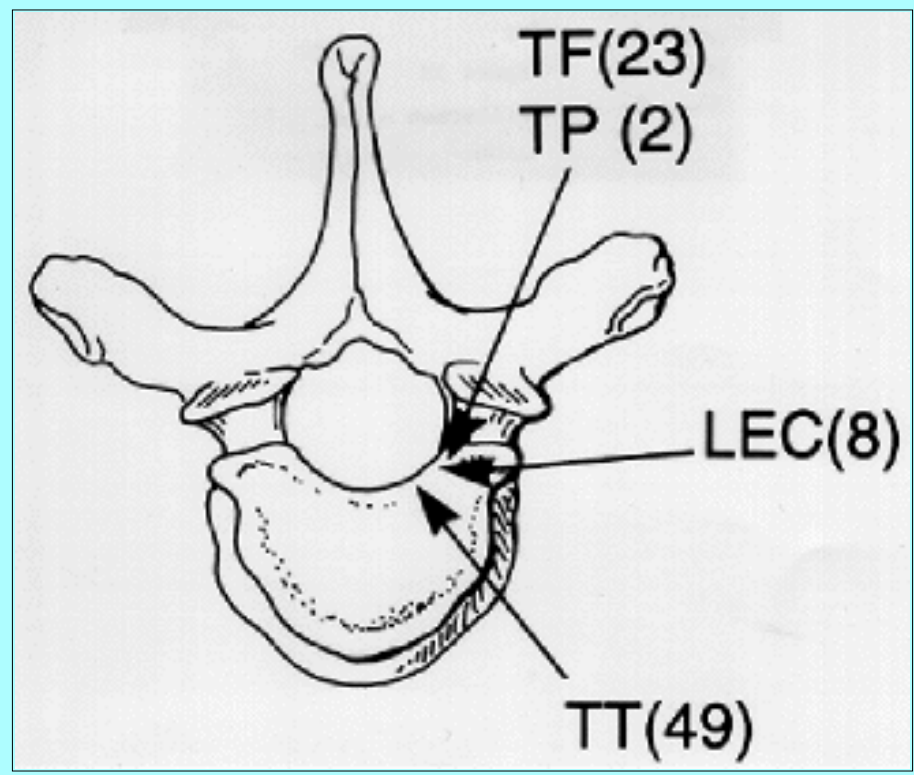

Fig. 3. Illustration depicting the four approaches used in this series and their respective trajectories. The transthoracic (TT) approach provides an anterolateral orientation, whereas the lateral extracavitary (LEC) approach facilitates a "true" lateral exposure. An identical posterolateral entry to the disc is provided by the transfacet (TF) pedicle-sparing and transpedicular (TP) surgeries. Numbers given in parentheses indicate the number of discs involved.

\section{Evaluation of Treatment}

The extent of disc removal was generally evaluated postoperatively by means of an MR or CT study. Postoperative signs and symptoms were monitored by the treating surgeon and the patient over the course of multiple follow-up visits lasting at least 1 year or until the patient was stable neurologically.

\section{RESULTS}

\section{Postoperative Improvement in Signs and Symptoms}

Overall improvement or resolution of pain (localized, axial, or radicular) occurred in 47 (87\%) of 54 patients. Patients with a predominance of radiculopathy showed resolution or improvement in 10 (91\%) of 11 cases, axial pain improved or resolved in 19 $(90 \%)$ of 21 cases, and localized pain improved or resolved in $18(82 \%)$ of 22 cases. All patients who presented with pain and did not 
improve following surgery were managed conservatively. Improvement or resolution of hyperreflexia and spasticity was noted in 39 (95\%) of 41 patients, sensory changes in $36(84 \%)$ of 43 , and bladder dysfunction in $13(76 \%)$ of 17 . Those patients with motor deficits demonstrated the least improvement, with only 25 (58\%) of 43 patients achieving functional improvement following decompression (Fig. 4).

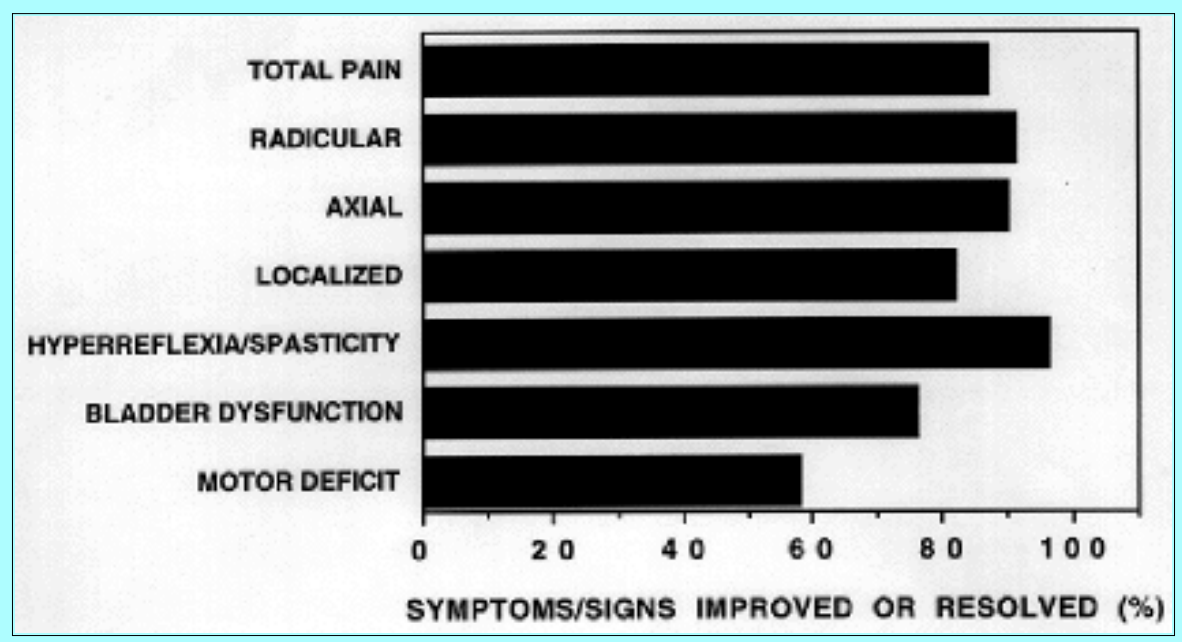

Fig. 4. Bar graph showing surgical results. Of patients presenting with pain, 87\% showed significant improvement or resolution of their pain syndrome. Patients with motor deficits demonstrated the least improvement, at $58 \%$.

\section{Correlation Between Disc Characteristics and Surgical Approaches and Outcome}

No correlation could be found between the disc level, consistency, size, position within the spinal canal, relation to the dura, and the patient's initial presentation and surgical outcome. There was no statistically significant difference in neurological outcome and pain improvement between the four surgical groups.

\section{Surgical Complications}

The complications from surgery in this series are listed in Table 1. The overall complication rate was based on $12(14.6 \%)$ of 82 discs. Major complications were defined as death, deterioration in neurological status, any problem requiring further surgery, or a significant medical complication, and occurred in three patients with three (3.6\%) of 82 surgically treated discs. These complications consisted of one perioperative death, one patient with spinal instability requiring further surgical treatment, and one patient who developed a mild increase in preoperative paraparesis. The death occurred in a debilitated, elderly man who had a severe progressive spastic paraparesis. This patient (Case 1) underwent a lateral decompression for a calcified centrolateral herniation and died several weeks postoperatively from cardiopulmonary compromise. The second patient (Case 2) required further surgery after developing a flexion deformity following a transfacet pedicle-sparing approach for a densely calcified, large centrolateral herniation. The third major complication involved a mild permanent increase in the preoperative paresis following a lateral extracavitary decompression. The nine minor complications consisted of one stable compression fracture following a transthoracic surgery that required the patient to remain in a brace for 3 months; one transient paraparesis that completely resolved after 48 hours; three superficial wound infections; three cases of pneumonia, and one postoperative seizure. All minor complications were treated medically with no sequelae.

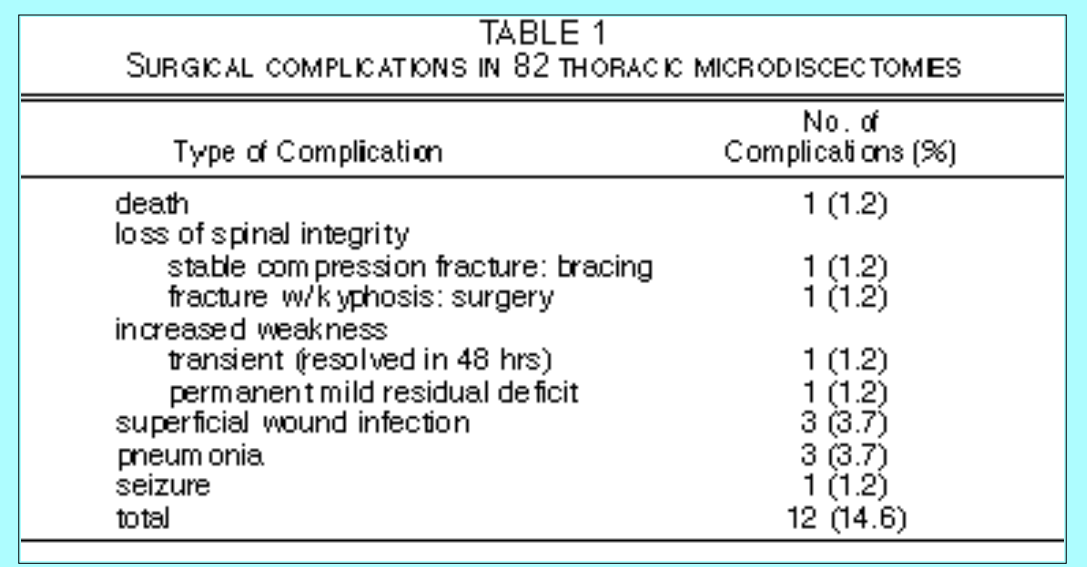

\section{ILLUSTRATIVE CASES}

\section{Case 1}

Excessive Surgery in a High-Risk Patient. This 77-year-old man presented with a history of rapidly progressing lower-extremity 
weakness and urinary incontinence. He reported a long history of midthoracic nonradiating pain. His medical history was notable for chronic renal failure, chronic obstructive pulmonary disease, coronary artery disease, and insulin-dependent diabetes. The CT studies (Fig. 5) revealed a large partially calcified centrolateral disc at T7-8. There was a significant degree of spinal cord deformation with displacement from left to right. However, this did not result in draping of the spinal cord around the disc. It is also important in the selection of surgical approach to be sure that the calcified portion of the disc is not in contact with the dura. The patient's symptoms did not improve or plateau with bedrest and high-dose steroid medication administration. A left lateral extracavitary approach was selected for disc removal and was performed without incident. After surgery the patient developed severe medical problems and died several weeks postoperatively from cardiopulmonary complications. Subsequently we have adopted less invasive surgeries in select situations, which include the high-risk medical patient.

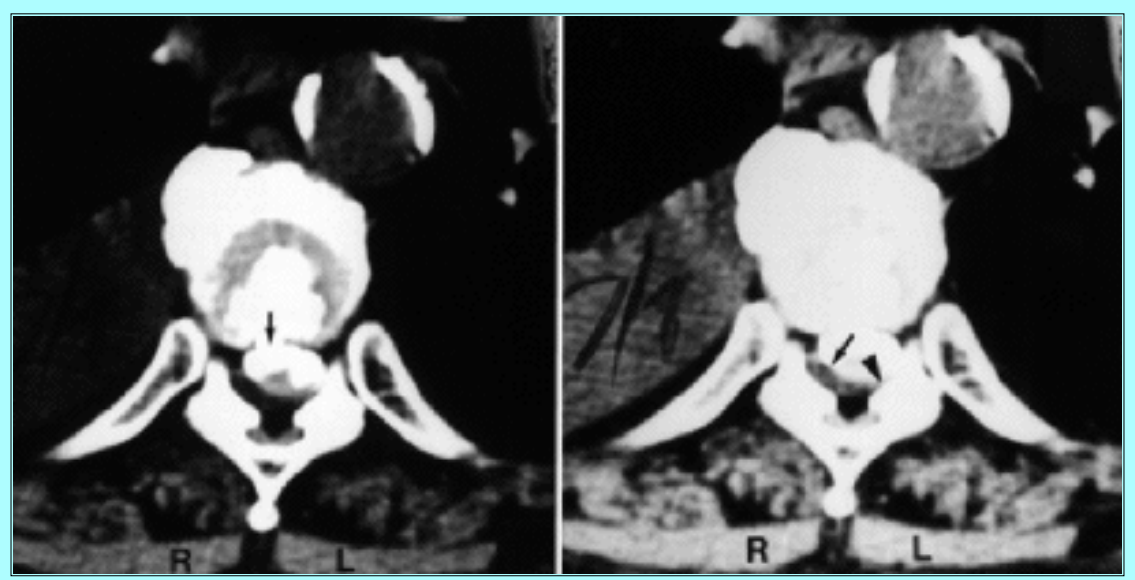

Fig. 5. Case 1. Intrathecal CT scans demonstrating a large partially calcified centrolateral T7-8 disc herniation. Left: The calcified portion of the disc herniation (arrow) involves the ventral aspect of the disc and is contiguous with the calcification inside the disc space. Of particular clinical importance is the lack of calcification in the dorsal aspect of the herniation. This indicates that the disc is not densely adherent to the ventral dura. Dural adherence may complicate disc removal and should be identified preoperatively. This helps facilitate selection of a suitable approach enabling safe discectomy, dural closure (grafting), and/or intradural disc removal. Right: The arrow points to the significantly deformed and posterolaterally displaced spinal cord. Note that although the spinal cord "caps" the right central dorsal aspect of disc, the left lateral disc margin (arrowhead) appears not to be covered by the spinal cord. This appearance indicates that dural manipulation can be avoided when performing a left-sided lateral or posterolateral approach. A left lateral extracavitary approach was used in this high-risk, elderly patient.

\section{Case 2}

Anterior, Anterolateral, and Lateral Approaches for Densely Calcified Large Centrolateral Herniations. A posterolateral approach was selected in this elderly woman who suffered from pain and mild myelopathy (Fig. 6). This approach was prematurely terminated not because of difficulty in visualizing the ventral dura, but because of the risk involved in removing the densely adherent calcified centrolateral disc. In this case an aggressive vertebral body resection above and below the calcified disc was performed in an effort to remove safely the portion of the disc that was firmly adherent to the ventral dura. The amount of vertebral body removed, together with the patient's advanced osteoporosis, resulted in a compression fracture with kyphosis. This required subsequent surgery for decompression, stabilization, and fusion. 


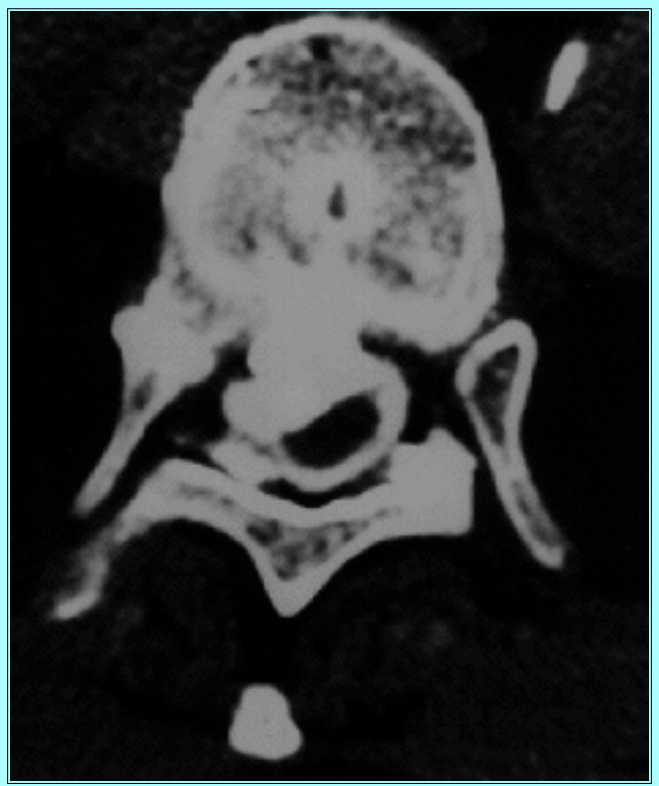

Fig. 6. Case 2. Intrathecal CT scan showing a large, densely calcified, centrolateral disc in an elderly woman presenting with pain and mild myelopathy. Posterolateral access to the herniation did not facilitate disc removal secondary to significant dural adherence. A postoperative compression fracture with an associated flexion deformity was thought to have occurred as a result of the patient's advanced osteoporosis and an aggressive bone removal to help ensure safety during dissection of disc from the ventral dura. The patient's pain worsened, requiring further surgery for decompression, stabilization, and fusion.

\section{DISCUSSION}

\section{Management Problems}

The management of thoracic disc herniations has historically been difficult. The reasons for this are multifactorial, and include the following.

Delays in Diagnosis. The rarity of symptomatic herniated thoracic discs has undoubtedly led to delays in diagnosis in the past. It is known that the annual incidence of thoracic disc herniations causing neurological deficits is one per 1,000,000 population. However, it has been estimated that 15 to $20 \%$ of the population have an incidental thoracic disc herniation visible on MR images. [3,4,56,59,76] Currently, MR imaging has largely replaced CT and myelographic studies for initial evaluation of thoracic discs.[27,35,47,59,76] In addition to the noninvasive nature of this modality, it provides excellent soft-tissue resolution using combinations of proton density $\mathrm{T}_{2}{ }^{-}$ and $\mathrm{T}_{1}$-weighted images. Exquisite details of disc herniations including intracanalicular location and disc size, as well as intrinsic spinal cord edema can be visualized using this modality. "Myelographic-equivalent" images in which $\mathrm{T}_{2}$-weighted signal sequences are used are possible. The potential disadvantages of MR imaging include: 1) difficulty distinguishing hard and soft disc herniations (that is, presence of calcification); 2) overestimation of the extent of spinal cord deformation; and 3) possible difficulty in localizing the disc level involved. When these issues are in doubt we generally obtain a myelographic study; a postmyelography CT scan can be helpful in evaluating the disc consistency and degree of spinal cord deformity. Myelography can also enable rib counting for the purpose of localization.

The lack of a characteristic presentation pattern for herniated thoracic discs has also contributed to delays in diagnosis. Although the majority of patients have pain, nearly $25 \%$ of the patients in this series had no pain on presentation. Furthermore, when this symptom was present, three distinct pain patterns were elucidated. Although myelopathy was commonly observed, findings varied significantly between individuals.

Presently there is a growing awareness of an increased incidence of this disorder, $[10,56,57,73]$ which we hope will lead to earlier detection and treatment, with improved outcomes.

Lack of Consensus on Indications for Disc Removal. Uncertainty regarding the natural history of this disease has made it difficult to define surgical indications. Awwad, et al.,[4] recently reported that no radiological distinction between symptomatic and asymptomatic discs could be made on postmyelography CT scans. Prophylactic surgery for these lesions is generally avoided; however, this preference has not been based on controlled, prospective studies.[4,10,68] Serial MR imaging may help facilitate longitudinal studies of patients with thoracic disc herniation both with and without symptoms that are treated medically. We generally reserve surgery for patients with severe, intractable radicular pain or those with myelopathy, especially when it is progressive or severe.

Variability of Surgical Approaches. A historical review of laminectomy for the treatment of thoracic disc herniations published by 
Logue[38] revealed disappointing results.[31,68] Several cornerstones for the surgical management of ventral thoracic spine disease have evolved from the need to improve these results.

The posterolateral surgeries, that is, transpedicular and transfacet pedicle-sparing approaches, are considered by many to be simpler operations than their anterolateral and lateral counterparts.[7,24,36,48-50,66,67] The anterolateral (transthoracic, thoracoscopic, retropleural thoracotomy) and lateral (lateral extracavitary, costotransversectomy, and parascapular) operations may require 1) performance of extensive muscle dissection or a thoracotomy; 2) the removal of a rib; 3) working with the disc interposed between the surgeon and spinal cord; 4) the need to detach part of the diaphragm at the thoracolumbar junction; 5) chest tube placement; and 6) treatment of significant perioperative pain. Although controversial, the possibility of vascular compromise to the spinal cord exists from disruption of the artery of Adamkiewicz during a lateral approach. This possibility leads us to obtain a spinal angiogram prior to performing one of these procedures between T-8 and L-1, because the contents of the neuroforamina are usually disrupted, thus sacrificing this terminal artery if present. The anterior and anterolateral approaches do not necessitate the sacrifice of the contents of the neuroforamina including the major radicular artery. In our series, in one patient ( $12.5 \%$ of those undergoing angiography) the major radicular artery of Adamkiewicz was found at the proposed site of discectomy. In this situation we would either operate from the opposite side or select an alternative exposure.

Each surgical approach carries the potential for a unique set of complications. These complications must be appreciated so that they can be avoided; comprehensive discussions of the approaches and their respective complications have been presented elsewhere.[1-3,5,7,9,10,14,17,20-23,25,26,28,29,34,36-39,41,43-45,56,58,60-65,67,68,69]

No universally accepted selection criteria exist to help the surgeon choose the best operation for disc removal. Moreover, no single surgical approach is best suited for all situations. As physicians become more familiar with these approaches they are better able to individualize surgical management, which will likely reduce associated morbidity. We have developed surgical selection guidelines based on our experience with the anterolateral and lateral approaches,[66-70] the well-documented success of others using the posterolateral transpedicular approach,[24,36,48-50] preliminary reports of new anterolateral techniques including the retropleural thoracotomy[42] and thoracoscopic surgeries, $[19,30,32,41,55,58,73]$ and our preliminary experience with the transfacet pedicle-sparing approach[66,67] (Fig. 7).

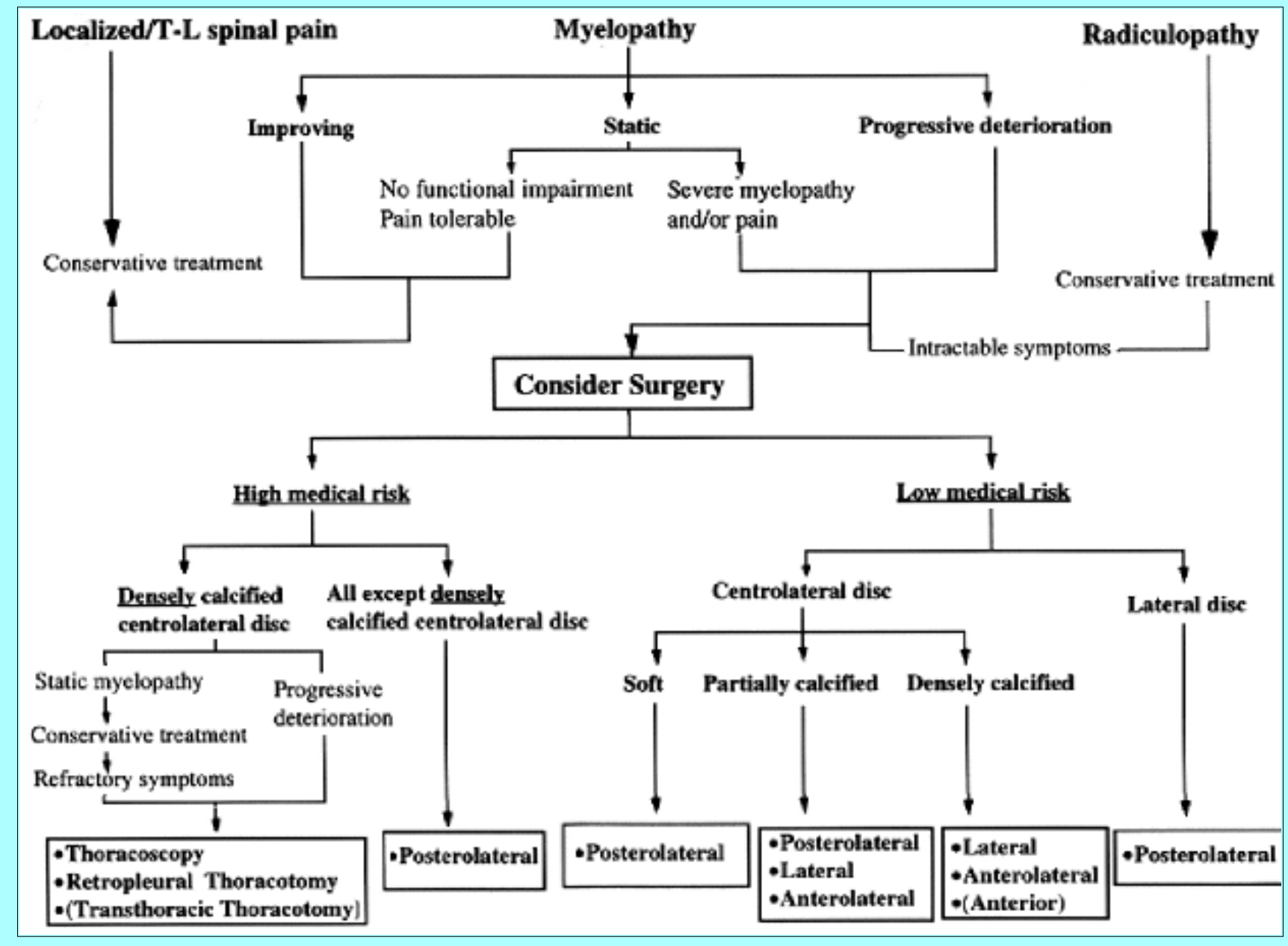

Fig. 7. Chart showing authors' current management scheme for treating symptomatic thoracic disc herniations.

Factors that also influence this treatment algorithm include presenting signs and symptoms, medical condition of the patient, disc size and location, extent of calcification, degree of spinal cord deformation, and the presence of dura surrounding the posterolateral margins 
of the disc. Our first 51 patients were treated by means of the transthoracic and lateral extracavitary approaches. Although these approaches enable the surgeon to achieve total disc removal with good results in improving myelopathy, radicular pain, and localized thoracic pain, they are extensive procedures from the standpoint of operating time, perioperative pain, and physiological stress to the patient.[68] During the last 6 years of the series we began exploring alternative, less invasive surgical options. During this period, $70 \%$ of the last 20 patients in our series underwent disc removal in which the transfacet pedicle-sparing operation was performed. Overall, $28 \%$ of discs were removed using this technique. Encouraging preliminary results have been published previously.[66,67] Our current experience leads us to recommend the posterolateral approaches for all symptomatic soft, lateral calcified, and selected calcified centrolateral herniations. The anterolateral approaches, including the transthoracic, thoracoscopic, and retropleural exposures and the lateral surgeries are presently reserved for selected densely and partially calcified centrolateral discs.

\section{Series Analysis}

Arce and Dohrmann,[1,2] Benjamin,[5] and others[3,5,7,12,38,50,52,61,65] have independently published literature reviews of thoracic disc series. These provide an excellent historical perspective and include surgeries performed earlier than the 1930 s. To better understand the overall effectiveness of modern thoracic disc herniation management we focused a review of the literature on more recent series that were reported during the past decade[7-9,18,20,23,36,37,43,46,56,64,65] (Table 2). To help measure outcomes in our series, we compared our experience with this contemporary collection (Table 3 ).

TABLE 2

REYIEW OF THORACK DISC SER ES PUELLSHED BETWEEN 1986 AND $1997 \star$

\begin{tabular}{|c|c|c|c|c|c|c|c|c|c|c|c|}
\hline \multirow[b]{3}{*}{ Authors \& Year } & \multirow[b]{3}{*}{$\begin{array}{l}\text { Surgical } \\
\text { Approach }\end{array}$} & \multirow[b]{3}{*}{$\begin{array}{c}\text { Plsi } \\
\text { Discst }\end{array}$} & \multicolumn{4}{|c|}{ PrelPost } & \multirow{2}{*}{\multicolumn{2}{|c|}{ Major Complications }} & \multirow{2}{*}{\multicolumn{2}{|c|}{ Mi nor Complications }} & \multirow{3}{*}{$\begin{array}{l}\text { Total } \\
\% \text { of } \\
\text { Compli- } \\
\text { calions }\end{array}$} \\
\hline & & & \multicolumn{2}{|c|}{ Pain } & \multirow[b]{2}{*}{$\begin{array}{l}\text { Motor } \\
\text { Deficit }\end{array}$} & \multirow{2}{*}{$\begin{array}{l}\text { Bowell } \\
\text { Bladder } \\
\text { Dys }\end{array}$} & & & & & \\
\hline & & & Back & $\begin{array}{l}\text { Radc- } \\
\text { ular }\end{array}$ & & & No. $(\%)$ & Description & No. $(\%)$ & Description & \\
\hline $\begin{array}{l}\text { Lesoin, et al., } \\
1986\end{array}$ & $\begin{array}{l}\operatorname{lam}, 3 \\
\text { MTP, 16; } \\
\text { TT, } 2\end{array}$ & $21: 22$ & NR & $5: 5$ & $16: 10$ & NR & $1(4.5)$ & \multirow[t]{2}{*}{ paraparesis perm } & \multirow[t]{2}{*}{$1[4.5]$} & \multirow[t]{2}{*}{ paraparesis trans } & \multirow[t]{2}{*}{9} \\
\hline $\begin{array}{l}\text { Bi um enkopf, } \\
1988\end{array}$ & $\begin{array}{l}\text { TT, } 4 \\
\text { TP, } 3\end{array}$ & $9: 7 \ddagger$ & $7: 7$ & 4.4 & $3: 2$ & $1: 1$ & NR & & & & \\
\hline $\begin{array}{l}\text { Bohlman \&Zde } \\
\text { blick, } 1988\end{array}$ & $\begin{array}{l}\text { cossto, 11; } \\
\text { TT, } 8\end{array}$ & $19: 22$ & $13: 10$ & $\begin{array}{l}4: 1 \\
\text { \&NR }\end{array}$ & $14: 12$ & $\begin{array}{c}8: 2 \\
8 \text { 外R }\end{array}$ & $2[9.1]$ & $\begin{array}{l}1 \text { paraparesis perm } \\
1 \text { wrong level; redo sx }\end{array}$ & $1(4.5)$ & paraparesis trans & 13.6 \\
\hline $\begin{array}{l}\text { Otani, th al., } \\
1988\end{array}$ & mc osto, 23 & $23: 23$ & NR & NR & $23: 23$ & 23:18 & NR & & & & \\
\hline $\begin{array}{l}\text { El-Kalliny, } \\
\text { al., } 1991\end{array}$ & $\begin{array}{l}\text { TP. 8; } \\
\text { TT, 8; } \\
\text { costo, } 5\end{array}$ & $21: 23$ & $15: 11$ & $13: 11$ & $10: 8$ & $6+N R$ & $3(13)$ & $\begin{array}{l}1 \text { paraparesis pem; TT } \\
1 \text { pleural effusion; sx } \\
\text { for CSF leak; TT } \\
1 \mathrm{CVA}\end{array}$ & $1(4.3)$ & pleural effusion & 17.4 \\
\hline $\begin{array}{l}\text { Singounas, et } \\
\text { al., } 1992\end{array}$ & $\begin{array}{l}\text { costo, } 10 \\
\text { meosto, } 4\end{array}$ & $14: 14$ & NR & NR & NR & NR & 3 [21.4] & $\begin{array}{l}1 \text { para paresis } \\
1 \text { dscibis } \\
1 \text { con pression fx } \\
\text { from discitis }\end{array}$ & NR & & 21.4 \\
\hline $\begin{array}{l}\text { Dietze \& Fes- } \\
\text { sler, } 1993\end{array}$ & LEC, 17 & $17: 22$ & $15: 10$ & & $7: 5$ & $8: 8$ & & & $2[9.1]$ & $\begin{array}{l}1 \text { anesthesia dolo- } \\
\text { rosa } \\
1 \text { pneumoria }\end{array}$ & 9.1 \\
\hline $\begin{array}{l}\text { Le Roux, et al., } \\
1993\end{array}$ & $\mathrm{TP}, 20$ & $20: 23$ & $17: 14$ & $17: 16$ & $3: 3$ & $1: 1$ & NR & & & & \\
\hline $\begin{array}{l}\text { Oppen heim, } \\
\text { et al., } 1993\end{array}$ & costo, 8 & $12: 8 \S$ & $7: 6$ & & NR & $1: 1$ & 1 [ 12.5$]$ & $\begin{array}{l}\text { wrong diagnosis; } \\
\text { progressive weak- } \\
\text { ness; Avlw found } \\
3 \text { levels; op cauda } \\
1 \text { level }\end{array}$ & & & 12.5 \\
\hline $\begin{array}{l}\text { Ridenoux, et } \\
\text { al., } 1993\end{array}$ & $\begin{array}{l}\operatorname{lam}, 4 ; \\
\text { TP, 12; } \\
\text { costo, } 15\end{array}$ & $31: 33$ & $11: 7$ & $12: 5$ & $18: 9$ & $13: 8$ & $3[9.1)$ & $\begin{array}{l}1 \text { increased myelo- } \\
\text { pat ly } \\
1 \text { wrong level; addi- } \\
\text { tional sx } \\
1 \text { incomplete disc } \\
\text { removal r redo sx }\end{array}$ & $3[9.1]$ & $\begin{array}{l}\text { superficial } \\
\text { wound inf ection }\end{array}$ & 18.2 \\
\hline $\begin{array}{l}\text { Simpson, 사 } \\
\text { al., 1993 }\end{array}$ & $\begin{array}{l}\operatorname{mcost} 0,16 \\
T P, 5\end{array}$ & $21: 23$ & $19: 19$ & & 6.4 & $4: 3$ & NR & & NR & & \\
\hline $\begin{array}{l}\text { Currex, et al., } \\
1994\end{array}$ & $\mathrm{TT}, 19$ & $19: 22$ & $15: 10$ & & $11: 7$ & $6+N R$ & $3(13.6)$ & $\begin{array}{l}1 \text { norfatal PE } \\
1 \text { intraop hem odymamic } \\
\text { instability; v tach \& } \\
\text { hypotension } \\
1 \text { spinal insta bility; } \\
\text { kyphosis postlam } \\
\text { \& TT }\end{array}$ & $9(41)$ & $\begin{array}{l}1 \text { incisi onal hemia } \\
1 \text { dural tear; intra- } \\
\text { op repair \& dain } \\
2 \text { bans urinary re- } \\
\text { tention } \\
2 \text { UTIs } \\
4 \text { ctronic thorac:o- } \\
\text { tomy pain }\end{array}$ & 54.6 \\
\hline $\begin{array}{l}\text { Bilsky \& Pat- } \\
\text { terson, } 1998\end{array}$ & $\mathrm{TP}, 20$ & $20: 20$ & $7: 5$ & 6.4 & $11: 11$ & $6: 5$ & & & $3(15)$ & $\begin{array}{l}1 \text { pseudom eningitis } \\
1 \text { deep woundin } \\
\text { fection } \\
1 \text { brans increase in } \\
\text { myelopatry }\end{array}$ & 15 \\
\hline
\end{tabular}

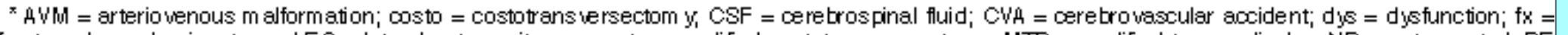

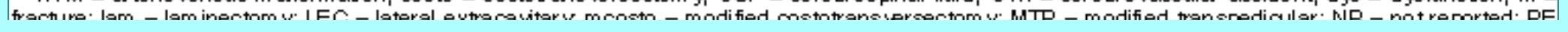




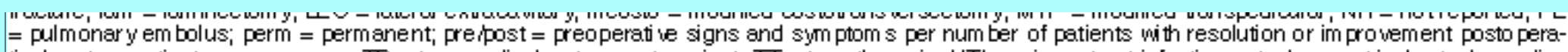
ti wel y, pts = patients; $s \mathrm{x}=$ surgery, TP = transpedicular; trans = transient; $T$ = transthoracic; UTI = urinary tract infection; $v$ tach = ienticular tachycardia

$\dagger$ Refers to the num ber of patients com pared with the number of discs treated.

$\ddagger$ Seven discs treated surgicall $y, 2$ treated conser wati vely.

s Eight discs treated surgicall $y, 4$ treated conser vati vel $y$

Demographics and Disc Characteristics. Thirteen series published between 1986 and 1997 were reviewed. More than half of the group reviewed consisted of series reported after 1992. A total of 263 discs were removed from 247 patients. Demographic and disc characteristic information can be found in Table 3. Statistical tests comparing the number of patients and discs removed, age, sex, incidence of trauma, and total levels involved showed no difference between the two groups. With regard to disc location in the spinal canal, central/centrolateral and laterally positioned discs were observed in $77 \%$ and $23 \%$, respectively, in the review group and $94 \%$ and $6 \%$ in ours. This discrepancy may reflect the lack of a uniform evaluation scheme between the different series. Most authors did not report the method used for this determination. Discs in our series were classified as centrolateral if the bulk of the herniation was medial to the lateral margin of thecal sac and lateral if the majority of disc was lateral to the dura. There is an increasing awareness of the relatively rare intradural[15,71,75,77] and multilevel[6,11,13,51] (symptomatic) herniations. The incidence of intradural disc extension in the review series was 5.6\% compared with the $7.3 \%$ seen in our series. In the review group $20(8 \%)$ of 242 patients were found to have multiple herniated discs, compared with 10 (14\%) of 71 patients in our series. According to the Fisher probability test this difference was not statistically significant. Finally, disc consistency is also an important parameter influencing treatment.[33,74 ] Sixty-five percent of discs were classified as at least partially calcified in our series based on either plain x-ray films, CT or MR studies, or intraoperative inspection. This was significantly greater than the $21.8 \%$ seen in the review group.

\begin{tabular}{|c|c|c|}
\hline \multicolumn{3}{|c|}{$\begin{array}{c}\text { TABLE } 3 \\
\text { COMPARISON BETWEEN THE PRESENT STUDV AND EARLER } \\
\text { THORACK DISC SER ES }\end{array}$} \\
\hline Factor & $\begin{array}{c}\text { 13Contemporary Series } \\
{[1986-1997]}\end{array}$ & Present Study \\
\hline \multicolumn{3}{|c|}{ demographics \& disc characteristics } \\
\hline no. patientsino. discs & $247: 263$ & $\frac{71: 82}{37 \cdot 34(109 \cdot 1)}$ \\
\hline age & $18-79$ irs & $19-75$ irs \\
\hline trauma & $37 \%(59: 161)$ & $37 \%(26: 71)$ \\
\hline le vels (total) & T1-L1 (244) & T4-L1 (82) \\
\hline frequencydevel & $\begin{array}{l}\text { T8-9: } 17 \%(41) \\
\text { T11-12: } 16 \%(39) \\
\text { T10-11: } 11 \%(26)\end{array}$ & $\begin{array}{r}\text { T9-10: } 26 \%(21) \\
\text { T8-9: } 23 \%(19) \\
\text { T10-11: } 17 \%(14)\end{array}$ \\
\hline calcified & $22 \%(33: 151)$ & $65 \%(53: 82)$ \\
\hline in tradural & $6 \%(5: 90)$ & $7 \%(6: 82)$ \\
\hline \multicolumn{3}{|l|}{ canal location } \\
\hline centralicentrolat & $77 \%(113: 146)$ & $94 \%(77: 82)$ \\
\hline lat & $23 \%(33: 146)$ & $6 \%(5: 82)$ \\
\hline multiple dises & $8 \%(20: 242)$ & $14 \%(10: 71)$ \\
\hline \multicolumn{3}{|c|}{ presenting signs \& sym ptoms } \\
\hline localized kxial pain & $56 \%(111: 199)$ & $61 \%(43: 71)$ \\
\hline radicular pain & $51 \%(94: 185)$ & $16 \%(11: 71)$ \\
\hline sensory deficit & $64 \%(145: 226)$ & $61 \%(43: 71)$ \\
\hline bomel itladder deficit & $35 \%(72 \cdot 208)$ & $24 \%(17: 71)$ \\
\hline motor im pairm ent & $55 \%(114: 208)$ & $61 \%(43: 71)$ \\
\hline \multicolumn{3}{|l|}{ results $\dagger$} \\
\hline painhtotal & $76 \%(106: 140)$ & $87 \%(47: 54)$ \\
\hline $\begin{array}{l}\text { localizediaxal } \\
\text { radicular }\end{array}$ & $\begin{array}{l}80 \%(39: 49) \\
74 \%(29: 39)\end{array}$ & $\begin{array}{l}86 \%(37: 43) \\
91 \%(10: 11)\end{array}$ \\
\hline sensory deficit & NR & $84 \%(36: 43)$ \\
\hline bowel itladder deficit & $80 \%(47: 59)$ & $77 \%(13: 17)$ \\
\hline motor im paiment & $69 \%(65: 94)$ & $58 \%(25: 43)$ \\
\hline \multicolumn{3}{|c|}{$\begin{array}{l}\text { *NR }=\text { not reported. } \\
\text { † Number resolved or im proved total number of patients in groups re porting } \\
\text { this result. }\end{array}$} \\
\hline
\end{tabular}

Presenting Signs and Symptoms. The percentage of patients with back pain, sensory deficit, bowel or bladder dysfunction, and weakness is strikingly similar between groups (Table 3). The one exception was that radiculopathy was seen in $51 \%$ of the review group and in only $16 \%$ of the patients in our series. A possible explanation for the small percentage of patients in our group with radicular pain and the higher percentage of those with back pain may relate to the classification criteria. In patients who complained of multiple pain syndromes, our group listed only the most severe one. Another possibility is the greater ratio of centrolateral/lateral herniations seen in our series (15:1) versus that seen in the review group (3:1); this may help explain the lower incidence of radicular pain in our patients.

Postoperative Results. A comparison of results between patient groups is illustrated in Table 3. The number of patients with resolution or improvement of a sign or symptom is divided by the total number of patients in the groups that reported outcomes pertaining to this problem. According to a chi-square test there was no statistically significant difference in results between the groups 
regarding pain, bowel/bladder dysfunction, or motor impairment.

Surgical Morbidity and Complications. The complications reported in the review group[7-9, 18,20,23,36,37,43,46,56,64,65] (Table

2) can be compared with those found in our series (Table 1). There was a $6.1 \%$ major complication rate in the review group (16 of 263 ) compared with a $3.6 \%$ rate (three of 82 ) in our series. Although our major complication rate was lower than that seen in the review group, this was not statistically significant (chi-square test). Additionally, there was one perioperative death in a high-risk medical patient in our group, and although several deaths have been reported in earlier series, $[1,2,5,38,52]$ there were none in the contemporary review groups. Minor complications involving $23(8.7 \%)$ of 263 herniated discs were seen in the review group and in nine (11\%) of 82 in our series. The total complication rate reported was 39 (14.8\%) of 263 in the review group and 12 (14.6\%) of 82 in our group. As with the major complications, no significant difference was seen in either the total complication rate or the minor complications. These percentages were in fact quite similar.

\section{Current Management Scheme}

Review of this series, with the attendant complications, in conjunction with review of other contemporary series has facilitated our decision-making process when considering the comprehensive management of these patients. Patients presenting with symptoms from a thoracic disc herniation are entered into one of three groups: localized/axial pain, radicular pain, or myelopathy (Fig. 7).

Localized/Axial Pain. These patients without myelopathy are not surgically treated. Conservative treatment may include the use of steroidal and nonsteroidal antiinflammatory drugs, bracing, activity modification, physical therapy, and steroid injections.

Radiculopathy. Patients with radiculopathy alone undergo aggressive medical treatment as outlined previously. On occasion, steroid injections into the intercostal nerve have been helpful diagnostically and therapeutically. Those with severe radicular complaints that do not improve are evaluated for surgery, which generally consists of a posterolateral approach for decompression.

Myelopathy. If imaging reveals a significant disc herniation in a patient with myelopathy, treatment is based on the status of the neurological deficit. Patients showing improvement are treated medically, as are those with static non-severe deficits without functional impairment or intolerable pain. When the myelopathy is either progressive or severe (static), patients are entered into a highor low-risk category.

A surgical approach is selected for all low-risk patients based on the position of the disc in the spinal canal. All patients with lateral herniations undergo posterolateral surgery. The degree and location of calcification within the disc herniation determines the approach selected for centrolateral herniations in this low-risk group. In our experience the posterolateral surgical approach has been safe and effective in the treatment of all soft herniations, including those located centrally.[66,67] Specially designed instruments and, on occasion, open endoscopy are thought to enhance safety during disc removal.[36,66,67] These surgeries may represent the least invasive of all presently available techniques.[36,66,67] The disappointing results in our Case 1 (Fig. 5) led to the development of the transfacet pedicle-sparing approach. Cadaveric analysis demonstrated this exposure to be virtually identical to the transpedicular surgery,[66] while requiring less bone and soft-tissue disruption.

We additionally reasoned that avoidance of pedicle removal and performance of only a keyhole facetectomy would lead to back pain results superior to those reported in patients undergoing transpedicular disc removal.[36,48,66,67] Preliminary results have suggested this to be the case.

Other minimally invasive techniques (for example, thoracoscopy) may also be considered for treating central soft herniations.[30,32,58,67,73] Densely calcified discs treated in our series were likely to have dural adherence. This usually leads us to advocate one of the anterolateral approaches when removing a densely calcified centrolateral herniation having a significant central portion (Case 2; Fig. 6). In the rare instance in which a densely calcified central disc herniation occurs in the upper thoracic spine, an anterior approach may be considered. Densely calcified centrolateral discs that are more laterally positioned are treated with either an anterolateral or lateral approach. Mildly or partially calcified centrolateral herniations necessitate posterolateral, lateral, or anterolateral surgery depending on several factors, including: 1) the presence of the bulk of the disc in the middle of the spinal canal; 2) the extent of calcification involving the posterior disc margin, which is thought to influence the degree of dural adherence; 3 ) the point of contact between the disc and spinal cord; and 4) the extent of spinal cord draping around the disc. The last two points directly influence the effectiveness of a posterolateral or lateral approach in exposing the posterolateral disc margin.

In Case 1 (Fig. 5) the calcified portion of disc was anterior and not adjacent to the ventral dura. Consequently the potential for significant dural adherence was small. This was substantiated at surgery. Additionally, although preoperative images demonstrated considerable spinal cord retrodisplacement there was no significant draping of the spinal cord around the left disc. This enabled exposure of the entire ipsilateral disc herniation with a left lateral approach. The presence of significant draping of the spinal cord around the disc may require some elevation of the lateral dura during disc removal using a lateral approach. This situation may predispose patients to neural injury and is to be avoided.

High-risk medical patients who have a densely calcified centrolateral herniation are treated conservatively. If symptoms are progressive or do not improve, a retropleural, thoracoscopic, or, if necessary, a transthoracic procedure is performed. Those patients 
having herniations that are not densely calcified and centrolateral are surgically treated using a posterolateral decompression.

\section{CONCLUSIONS}

This review of our experience and that of other contemporary series has illustrated that the management of thoracic disc herniations still presents a significant challenge. Although complications have been dramatically reduced from earlier series, the need remains to refine treatment further. The fundamental question of which patients require surgery and who can be safely managed conservatively needs to be answered. This will require longitudinal evaluation of both symptomatic and asymptomatic patients managed nonsurgically. The appropriate management strategy should be based on the initial presentation, medical condition of the patient, and disc characteristics. Because all of the anterior, anterolateral, and lateral surgical approaches have the potential for significant morbidity, continued effort toward the development and refinement of minimally invasive treatments is necessary. Finally, it is imperative that treating clinicians maximize their ability to individualize treatment by maintaining proficiency in multiple surgical options.

\section{Acknowledgment}

The authors thank Lena Masri, M.S., for her statistical analysis of this series.

\section{References}

1. Arce CA, Dohrmann GJ: Herniated thoracic disks. Neurol Clin 3:383-392, 1985

2. Arce CA, Dohrmann GJ: Thoracic disc herniation. Improved diagnosis with computed tomographic scanning and a review of the literature. Surg Neurol 23:356-361, 1985

3. Arseni C, Nash F: Thoracic intervertebral disc protrusion. A clinical study. J Neurosurg 17:418-430, 1960

4. Awwad EE, Martin DS, Smith KR Jr, et al: Asymptomatic versus symptomatic herniated thoracic discs: their frequency and characteristics as detected by computed tomography after myelography. Neurosurgery 28:180-186, 1991

5. Benjamin V: Diagnosis and management of thoracic disc disease. Clin Neurosurg 30:577-605, 1983

6. Bhole R, Gilmer RE: Two-level thoracic disc herniation. Clin Orthop 190:129-131, 1988

7. Bilsky MH, Patterson RH: The transpedicular approach for thoracic disc herniations, in Benzel EC, Stillerman CB (eds): The Thoracic Spine. St Louis: Quality Medical (In press, 1998)

8. Blumenkopf B: Thoracic intervertebral disc herniations: diagnostic value of magnetic resonance imaging. Neurosurgery 23:36-40, 1988

9. Bohlman HH, Zdeblick TA: Anterior excision of herniated thoracic discs. J Bone Joint Surg (Am) 70:1038-1047, 1988

10. Borges LF: Thoracic disc disease and spondylosis, in Tindall GT, Cooper PR, Barrow DL (eds): The Practice of Neurosurgery. Baltimore: Williams \& Wilkins, 1996, pp 2461-2471

11. Boriani S, Biagini R, De Lure F, et al: Two-level thoracic disc herniation. Spine 19:2461-2466, 1994

12. Brown CW, Deffer PA Jr, Akmakjian J, et al: The natural history of thoracic disc herniation. Spine 17 (Suppl 6):S97-S102, 1992

13. Chin LS, Black KL, Hoff JT: Multiple thoracic disc herniations. Case report. J Neurosurg 66:290-292, 1987

14. Chou SN, Seljeskog EL: Alternative surgical approaches to the thoracic spine. Clin Neurosurg 20:306-321, 1973

15. Chowdhary UM: Intradural thoracic disc protrusion. Spine 12:718-719, 1987

16. Crafoord C, Hiertonn T, Lindblom K, et al: Spinal cord compression caused by a protruded thoracic disc. Report of a case treated with antero-lateral fenestration of the disc. Acta Orthop Scan 28:103-107, 1958

17. Curcin A, Lucas PR: Spondylolisthesis after posterolateral thoracic discectomy. Case report and literature review. Spine 17:1254-1256, 1992

18. Currier BL, Eismont FJ, Green BA: Transthoracic disc excision and fusion for herniated thoracic discs. Spine 19:323-328, 1994

19. Dickman CA, Rosenthal D, Karahalios DG, et al: Thoracic vertebrectomy and reconstruction using a microsurgical thoracoscopic approach. Neurosurgery 38:279-293, 1996

20. Dietze DD Jr, Fessler RG: Thoracic disc herniations. Neurosurg Clin North Am 4:75-90, 1993 
21. Dohn DF: Thoracic spinal cord decompression: alternative surgical approaches and basis of choice. Clin Neurosurg 27:611-623, 1980

22. Ebersold MJ: Surgical management of thoracic disc disease. Contemp Neurosurg 7:1-6, 1986

23. El-Kalliny M, Tew JM Jr, van Loveren H, et al: Surgical approaches to thoracic disc herniations. Acta Neurochir 11:22-32, 1991

24. Epstein JA: Comment on Sekhar LN, Jannetta PJ: Thoracic disc herniation: operative approaches and results. Neurosurgery 12:305, 1983

25. Fessler RG, Dietze DD Jr, Mac Millan M, et al: Lateral parascapular extrapleural approach to the upper thoracic spine. J

Neurosurg 75:349-355, 1991

26. Fidler MW, Goedhart ZD: Excision of prolapse of thoracic intervertebral disc. A transthoracic technique. J Bone Joint Surg (Br) 66:518-522, 1984

27. Francavilla TL, Powers A, Dina T, et all: MR imaging of thoracic disk herniations. J Comput Assist Tomogr 11:1062-1065, 1987

28. Garrido E: Modified costotransversectomy: a surgical approach to ventrally placed lesions in the thoracic spinal canal. Surg

Neurol 13:109-113, 1979

29. Ghanayem AJ, Bohlman HH: Transient paraplegia from intraoperative intercostal nerve block after transthoracic discectomy. Spine 19:1294-1296, 1994

30. Horowitz MB, Moossy JJ, Julian T, et al: Thoracic discectomy using video assisted thoracoscopy. Spine 19:1082-1086, 1994

31. Hulme A: The surgical approach to thoracic intervertebral disc protrusions. J Neurol Neurosurg Psychiatry 23:133-137, 1960

32. Krasna MJ, Mack MJ: Atlas of Thoracoscopic Surgery. St. Louis: Quality Medical, 1994, pp 206-211

33. Kumar A: Thoracic disc prolapse in calcified discs. Orthopedics 14:98-99, 1991

34. Larson SJ, Holst RA Hemmy DC, et al: Lateral extracavitary approach to traumatic lesions of the thoracic and lumbar spine. J

Neurosurg 45:628-637, 1976

35. Lehman LB: Paraparesis during myelography associated with a ruptured thoracic intervertebral disc. Neurosurgery 24:912-914, 1989

36. Le Roux PD, Haglund MM, Harris AB: Thoracic disc disease: experience with the transpedicular approach in twenty consecutive patients. Neurosurgery 33:58-66, 1993

37. Lesoin F, Rousseaux M, Autricque A, et al: Thoracic disc herniations: evolution in the approach and indications. Acta Neurochir 80:30-34, 1986

38. Logue V: Thoracic intervertebral disc prolapse with spinal cord compression. J Neurol Neurosurg Psychiatry 15:227-241, 1952

39. Maiman DJ, Larson SJ, Luck E, et al: Lateral extracavitary approach to the spine for thoracic disc herniation: report of 23 cases.

Neurosurgery 14:178-182, 1984

40. Maiman DJ, Pintar FA: Anatomy and clinical biomechanics of thoracic spine. Clin Neurosurg 38:296-324, 1992

41. McAfee PC, Regan JR, Zdeblick T, et al: The incidence of complications in endoscopic anterior thoracolumbar spinal reconstructive surgery. A prospective multicenter study comprising the first 100 consecutive cases. Spine 20:1624-1632, 1995

42. McCormick PC: Retropleural approach to the thoracic and thoracolumbar spine. Neurosurgery 37:908-914, 1995

43. Oppenheim JS, Rothman AS, Sachdev VP: Thoracic herniated discs: review of the literature and 12 cases. Mt Sinai J Med 60:321-326, 1993

44. Otani K, Manzoku S, Shibaski K, et al: The surgical treatment of thoracic and thoracolumbar disc lesions using the anterior approach. Report of six cases. Spine 2:266-275, 1977

45. Otani K, Nakai S, Fujimura Y, et al: Surgical treatment of thoracic disc herniation using the anterior approach. J Bone Joint Surg (Br) 64:340-343, 1982

46. Otani K, Yoshida M, Fujii E, et al: Thoracic disc herniation. Surgical treatment in 23 patients. Spine 13:1262-1267, 1988

47. Parizel PM, Rodesch G, Balériaux D, et al: Gd-DTPA-enhanced MR in thoracic disc herniations. Neuroradiology 31:75-79, 1989 
48. Patterson RH: Comment on Le Roux PD, Haglund MM, Harris AB: Thoracic disc disease: experience with the transpedicular approach in twenty consecutive patients. Neurosurgery 33:66, 1993

49. Patterson RH Jr: Comment on Sekhar LN, Jannetta PJ: Thoracic disc herniation: operative approaches and results. Neurosurgery 12:305, 1983

50. Patterson RH Jr, Arbit E: A surgical approach through the pedicle to protruded thoracic discs. J Neurosurg 48:768-772, 1978

51. Peker S, Akkurt C, Ozean OE: Multiple thoracic disc herniations. Acta Neurochir 107:167-170, 1990

52. Perot PL Jr, Munro DD: Transthoracic removal of midline thoracic disc protrusions causing spinal cord compression. J Neurosurg 31:452-458, 1969

53. Ransohoff J, Spencer F, Siew F, et al: Transthoracic removal of thoracic disc. Report of three cases. J Neurosurg 31:459-461, 1969

54. Ravichandran G, Frankel HL: Paraplegia due to intervertebral disc lesions: a review of 57 operated cases. Paraplegia 19:133-139, 1981

55. Regan JJ, Mack MJ, Picetti GD III: A technical report on video-assisted thoracoscopy in thoracic spinal surgery. Preliminary description. Spine 20:831-837, 1995

56. Ridenour TR, Haddad SF, Hitchon PW, et al: Herniated thoracic disks: treatment and outcome. J Spinal Disord 6:218-224, 1993

57. Rosenbloom SA: Thoracic disc disease and stenosis. Radiol Clin North Am 29:765-775, 1991

58. Rosenthal D, Rosenthal R, De Simone A: Removal of a protruded thoracic disc using microsurgical endoscopy. A new technique. Spine 19:1087-1091, 1994

59. Ross JS, Perez-Reyes N, Masaryk TJ, et al: Thoracic disk herniation: MR imaging. Radiology 165:511-515, 1987

60. Rossitti S, Stephensen H, Ekholm S, et al: The anterior approach to high thoracic (T1-T2) disc herniation. Br J Neurosurg 7:189-192, 1993

61. Russell T: Thoracic intervertebral disc protrusion: experience of 67 cases and review of the literature. Br J Neurosurg 3:153-160, 1989

62. Safdari H, Baker RL II: Microsurgical anatomy and related techniques to an anterolateral transthoracic approach to thoracic disc herniations. Surg Neurol 23:589-593, 1985

63. Sekhar LN, Jannetta PJ: Thoracic disc herniation: operative approaches and results. Neurosurgery 12:303-305, 1983

64. Simpson JM, Silveri CP, Simeone FA, et al: Thoracic disc herniation. Re-evaluation of the posterior approach using a modified costotransversectomy. Spine 18:1872-1877, 1993

65. Singounas EG, Kypriades EM, Kellerman AJ, et al: Thoracic disc herniation. Analysis of 14 cases and review of the literature. Acta Neurochir 16:49-52, 1992

66. Stillerman CB, Chen TC, Day JD, et al: The transfacet pedicle-sparing approach for thoracic disc removal: cadaveric morphometric analysis and preliminary clinical experience. J Neurosurg 83:971-976, 1995

67. Stillerman CB, Couldwell WT, Chen TC, et al: Thoracic disc. J Neurosurg 85:189-190, 1996 (Letter)

68. Stillerman CB, Weiss MH: Management of thoracic disc disease. Clin Neurosurg 38:325-352, 1992

69. Stillerman CB, Weiss MH: Principles of surgical approaches to the thoracic spine, in Tarlov E (ed): Neurosurgical Treatment of Disorders of the Thoracic Spine. Neurosurgical Topics. Park Ridge, Ill: American Association of Neurological Surgeons, 1991, pp $1-19$

70. Stillerman CB, Weiss MH: Surgical management of thoracic disc herniation and spondylosis, in Menezes AH, Sonntag VKH (eds): Principles of Spinal Surgery. New York: McGraw-Hill, 1996, pp 581-601

71. Stone JL, Lichtor T, Banerjee S: Intradural thoracic disc herniation. Spine 19:1281-1284, 1994

72. Terry AF, McSweeney T, Jones HWF: Paraplegia as a sequela to dorsal disc prolapse. Paraplegia 19:111-117, 1981

73. Theodore N, Dickman CA: Current management of thoracic disc herniation. Contemp Neurosurg 18:1-6, 1997

74. Wallace CJ, Fong TC, MacRae ME: Calcified herniations of the thoracic disk: role of magnetic resonance imaging and computed 
tomography in surgical planning. Can Assoc Radiol J 43:52-54, 1992

75. Wang AM, Zaman AA: Intradural herniation of thoracic disc: CT metrizamide myelography. Comput Radiol 10:115-118, 1986

76. Williams MP, Cherryman GR, Husband JE: Significance of thoracic disc herniation demonstrated by MR imaging. J Comput Assist Tomogr 13:211-214, 1989

77. Yildizhan A, Pasaoglu A, Okten T, et al: Intradural disc herniations. Pathogenesis, clinical picture, diagnosis and treatment. Acta Neurochir 110:160-165, 1991

Manuscript received April 29, 1997.

Accepted in final form November 11, 1997.

This work was presented in part at the Annual Meeting of the American Association of Neurological Surgeons, Minneapolis, Minnesota, 1996.

Address reprint requests to: Charles B. Stillerman, M.D., 20 Burdick Expressway West, Suite 401, Minot, North Dakota 58701. 